\title{
Measure for measure: using statistics to monitor service take-up of the University of Leicester Library's Distance Learning Unit
}

\author{
Lou McGill
}

\section{The author}

Lou McGill worked in special libraries for 15 years before taking up her current post as Distance Learning Services Librarian at the University of Leicester.

Email: 1km5@1e.ac.uk

\begin{abstract}
The new Distance Learning Unit at the University of Leicester Library needed to evaluate and measure take-up of services in order to secure funding beyond the initial three-year funding period. The Unit established a comprehensive procedure for recording transactions which included both manual and computer generated data. This data was presented in several different ways to different groups within the University. Statistics were collected to aid library management, provide information to academic departments and for broader University management. The quantitative data revealed a significant growth in all service areas and qualitative feedback has been very positive. Members of the team have experienced several positive outcomes as a result of collecting this information and are highly committed to this time consuming task.
\end{abstract}

\section{Introduction}

In December 1999 the University of Leicester Library established a new stand-alone service to cater for the needs of over 6,000 students studying through the mode of distance learning. The Distance Learning Unit was initially funded for three years. In order to demonstrate the value of the service and thus secure future funding, an effective means of evaluating and measuring the service was needed. This paper will identify the combination of quantitative and qualitative mechanisms used to measure the effectiveness of the Unit.

Initially staffed by a qualified librarian and three library assistants, the Unit now has a team of six library assistants. A new academic-related information librarian is currently being recruited. The Distance Learning Unit provides a range of specialised services to students based worldwide with varied language, cultural and geographical differences. Skill levels in relation to both IT and information retrieval also vary dramatically. Most students are mature students with full-time professional posts and family commitments. Some students do not have access to a computer or the Internet, whilst others may have access at either home or work or both.

The Unit offers document delivery in the form of printed and electronic articles and extracts of books, postal book loans for those living in the UK, and help with literature searches. The web site provides access to a range of electronic resources and a tailored gateway to the web catalogue. The Unit deals with about 300 enquiries a month, which range from simple requests for information about the service to complex questions to support the use of a wide range of electronic resources.

Categories of enquiry:

- Service information $(60 \%)$ 
- Help in using electronic resources (13\%)

- Library registration (12\%)

- Other $(15 \%)$

Methods of enquiry:

- Telephone $(42 \%)$

- E-mail (41\%)

- Personal visit (14\%)

- $\mathrm{Post} / \mathrm{Fax} / \mathrm{Web}$ form (3\%)

The Unit records statistics for most of these services and benefited from being able to include statistics collection in procedures as they were established. The specialised nature of the new Unit, and the existence of a team of people devoted to the provision of this service, provided a rare opportunity to set up procedures and training to facilitate the collection of data in an easily controlled environment.

\section{Reasons for collecting statistics}

Before discussing the different types of data that are recorded it is worth considering the three different reasons for collecting this type of information. Several groups within the University require information for specific purposes. This affects both the type of information we collect and the manner in which it is presented. Whilst there is some overlap between the three purposes they can be briefly described as:

- Library management information

- Academic department information

- University management information

\section{Library management information}

The collection of statistics to aid library management has been practised at differing levels in all types of libraries for many years. There is a useful bibliography on performance measurement and performance indicators available on the web (Robinson, 2000). Whilst the Distance Learning Unit services are included in the University Library's SCONUL statistical process (Winkworth,1999) several factors led to more detailed information being recorded.

It was important to monitor the workload within the Unit as the service developed. We needed to identify what level of service could be maintained within existing staffing levels. Although the Unit was officially open from December 1999, statistics for all service transactions were recorded from October 1999 due to early student requests being used to test out the new systems. By April 2000, after a period of steady growth in all services the figures revealed a dip in the number of library registrations completed. 


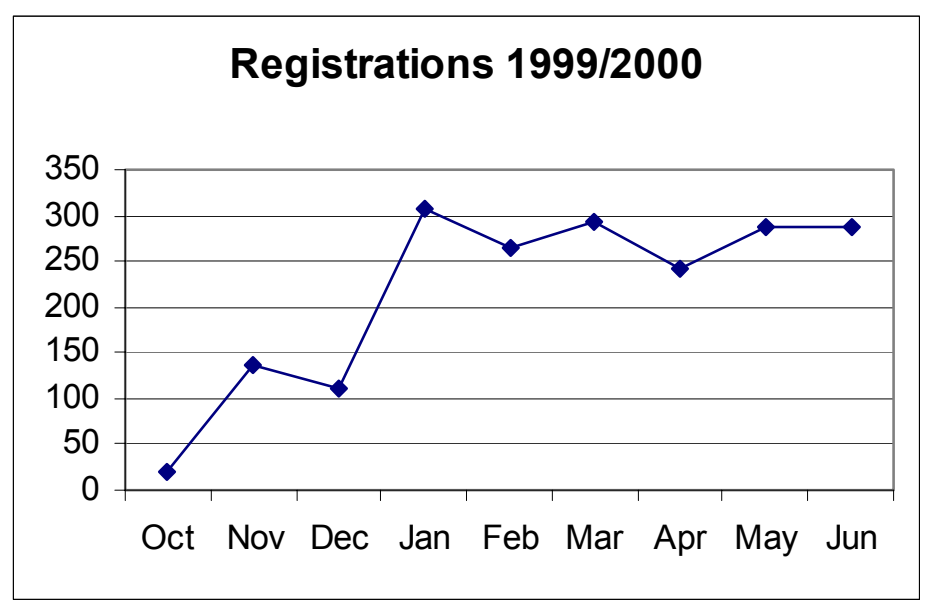

Fig. 1 Number of distance learning students registered with the Unit in the first year

Although the number of registration forms arriving in the Unit remained constant, the team had been unable to process them due to increases in other areas of service. These figures were presented to the library managers and resulted in some temporary extra staffing to keep up with this area of work.

Library management statistics are presented for each service as overall totals for each month, so that periods of heavy workload can be identified and planned for.

\section{Academic department information}

The same information also needs to be presented to individual academic departments in a format more appropriate to their needs. They also want to know if services are used by both UK and non-UK students. For this reason another set of charts are produced for each department, showing use patterns across the academic year. Several departments have used these statistics as evidence during QAA (The Quality Assurance Agency for Higher Education) subject review exercises and many plan to use the information for marketing purposes.

As an example, the following chart shows the number of Management Centre students registered with the Library from the UK and non-UK. The 'updated' category is for those students who had registered with the Library before the Unit was established and whose records needed to be altered for the new service.

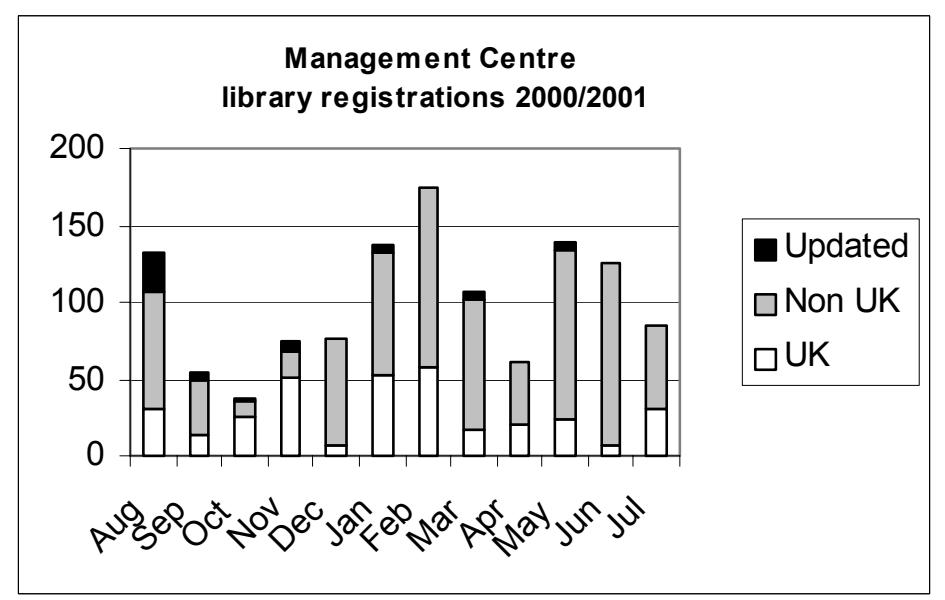

Fig. 2 Library registrations completed for Management Centre distance learning students 
This department has many students based outside the UK, and was therefore interested to know if those students were making effective use of the service. During the period 2000 to 2001 students had to register individually with the Unit to access the library service, which we have interpreted as an expression of interest in using the services. A new student registration system now means that all distance learning students will automatically be registered with the Library. This will make it harder to identify interest in the service but will provide a significant advantage in that all students will receive the registration pack including a printed 'Guide to services'.

This guide has encouraged use of services and an increase in the number of logins to the web catalogue. When the guide was first produced and sent to all registered students in March and April 2000, the number of logins rose accordingly.

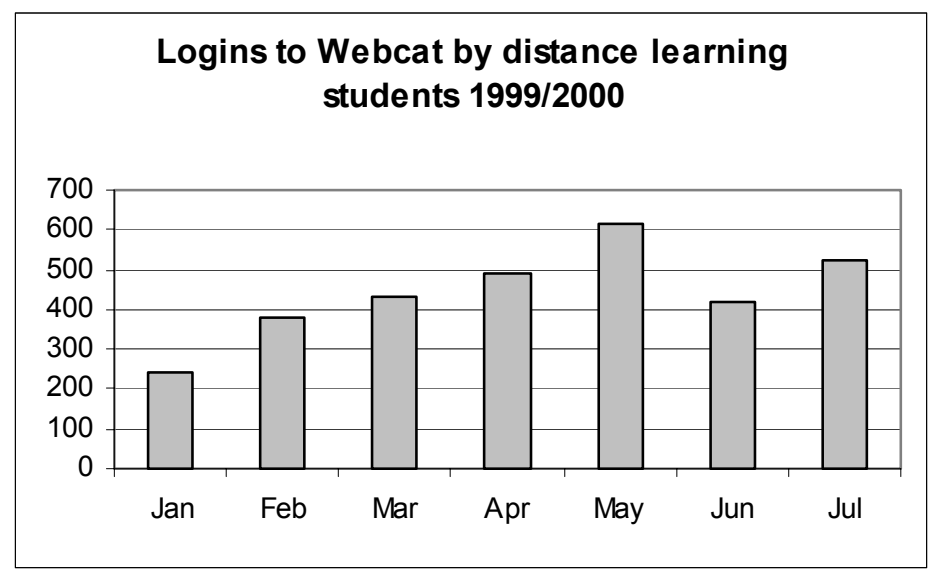

Fig. 3 Logins to the University Library web catalogue by distance learning students

Departments are also interested in finding out which services are most popular with their students and how use patterns vary at different times of the year, depending on students' progress during a course. For example, departments expect higher use of literature searching services and document delivery services when specific groups of students reach the dissertation stage of their course.

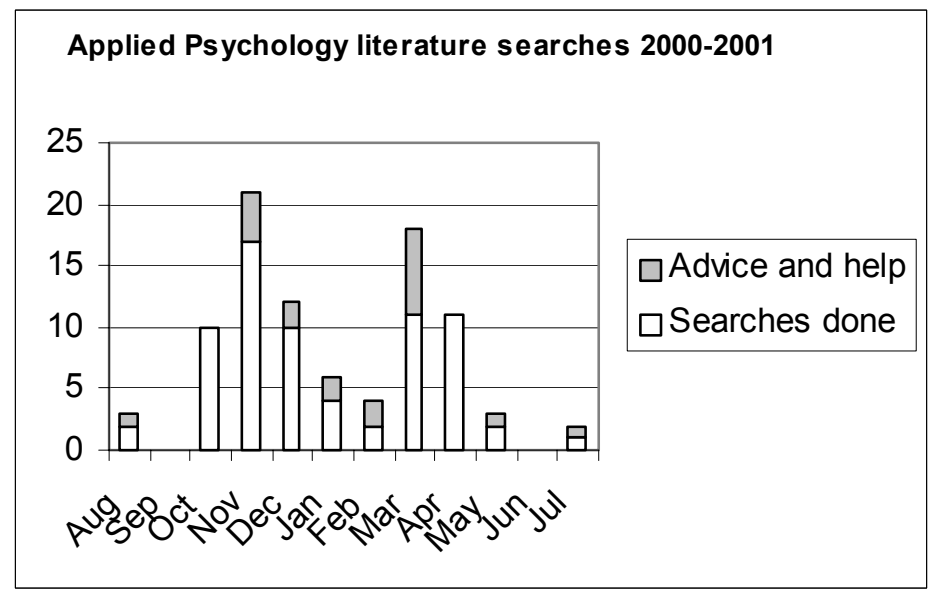

Fig.4 Pattern of use of the literature search service by Applied Psychology students 


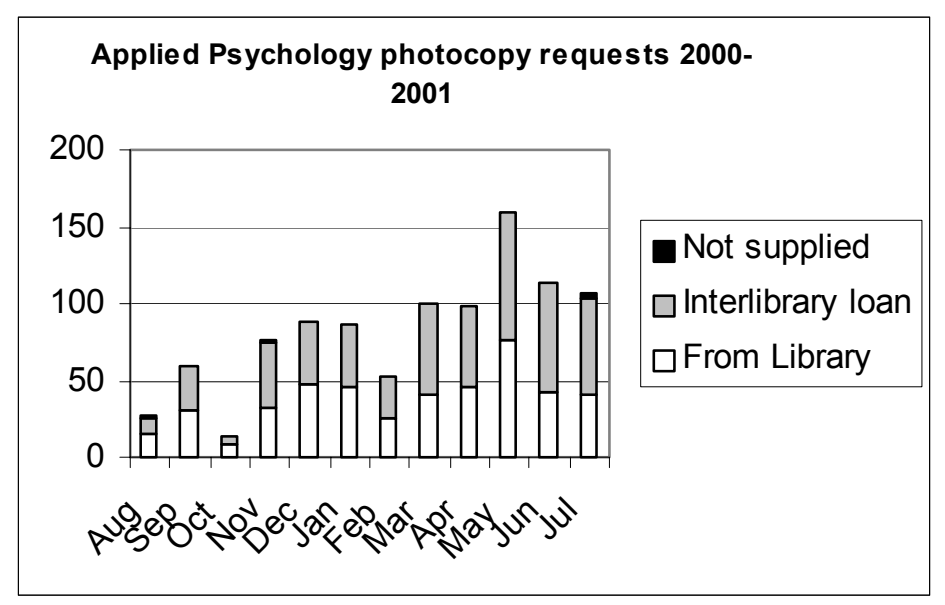

Fig.5 Pattern of use of the document delivery service by Applied Psychology students

Figures 4 and 5 reveal the patterns of service use for the Applied Psychology department for literature searches and document delivery services. The higher use period from March to July reflects the fact that students were preparing for their dissertations at this time of year.

\section{University management information}

The Unit also set up different views of the same data to provide information for the University managers about the take up of the service by students on different distance learning courses. This information is intended to justify the investment in such a service and encourage continued funding. In the Unit's first Annual Report registration data was presented in relation to the number of students registered with each department.

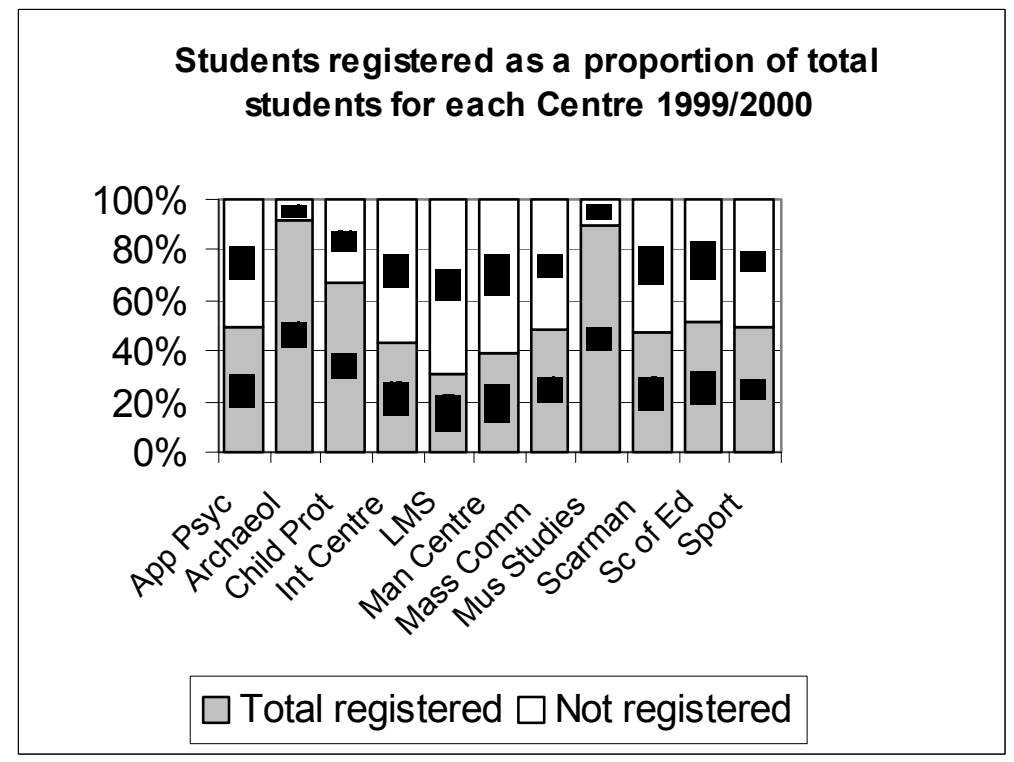

Fig. 6 Chart presented in the Unit's Annual Report 1999/2000

The Unit offered a lunchtime presentation to University managers and academic heads of department at the end of the first two years service. This session highlighted the success of the service and utilised the data collected to illustrate this. The following chart and table identified a significant increase in the use of all services. 


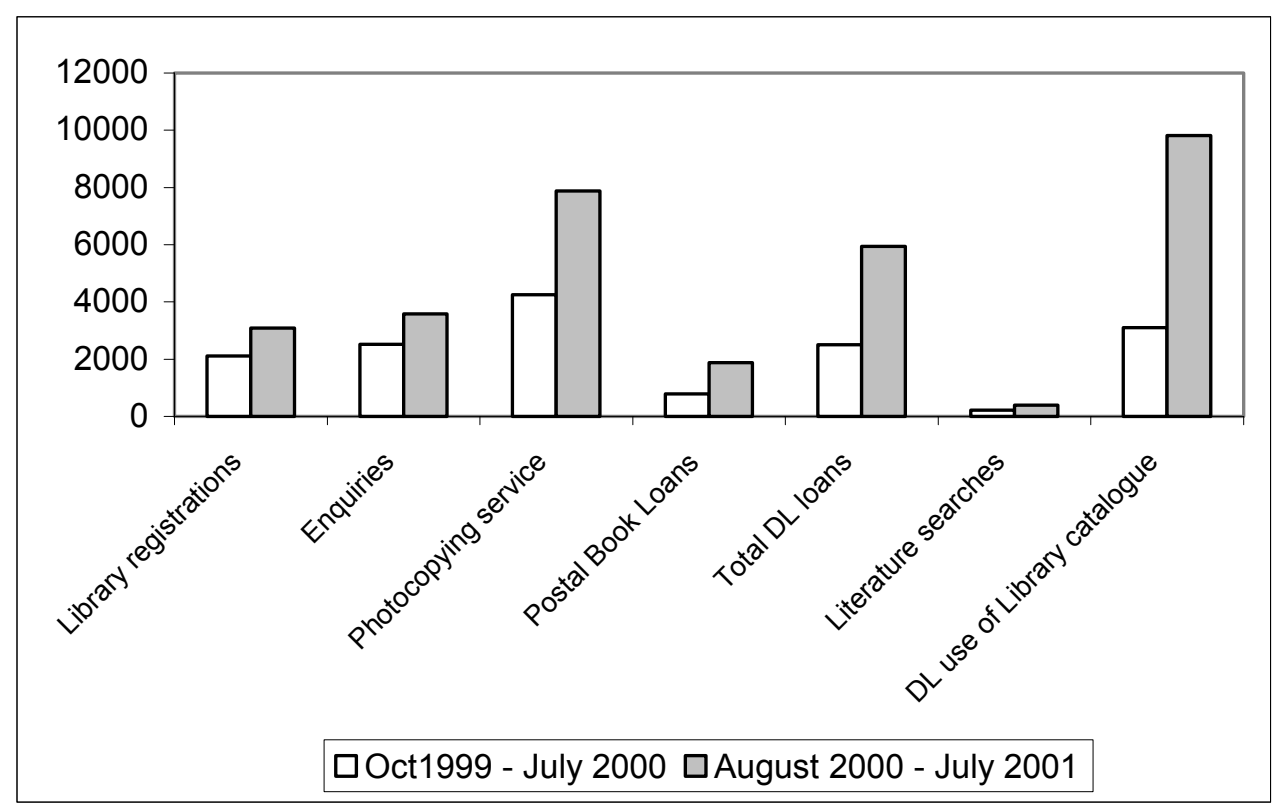

Fig. 7 Growth in service take-up during the first two years.

The accompanying table showed the percentage increase in use of each service.

\begin{tabular}{|l|c|c|c|}
\hline Service & $\begin{array}{c}\text { Oct 1999 - Jul } \\
\mathbf{2 0 0 0} \\
\mathbf{1 0 ~ m o n t h s}\end{array}$ & $\begin{array}{c}\text { Aug 2000 - Jul } \\
\mathbf{2 0 0 1} \\
\mathbf{1 2} \text { months }\end{array}$ & $\begin{array}{c}\text { \%age } \\
\text { increase }\end{array}$ \\
\hline $\begin{array}{l}\text { Students registered or re- } \\
\text { registered with the Distance } \\
\text { Learning Service }\end{array}$ & 2115 & 3089 & $+46 \%$ \\
\hline Enquiries received & 2515 & 3586 & $+43 \%$ \\
\hline $\begin{array}{l}\text { Photocopied articles and book } \\
\text { chapters supplied }\end{array}$ & 4256 & 7879 & $+85 \%$ \\
\hline $\begin{array}{l}\text { Postal Book Loans supplied } \\
\text { Total items borrowed (including } \\
\text { students own use of the } \\
\text { Libraries) }\end{array}$ & 2507 & 5935 & $+137 \%$ \\
\hline $\begin{array}{l}\text { Literature searches performed } \\
\text { for the users }\end{array}$ & 215 & 386 & $+80 \%$ \\
\hline $\begin{array}{l}\text { Logins via the Distance Learner } \\
\text { gateway to the Library catalogue }\end{array}$ & 3106 & 9820 & $+216 \%$ \\
\hline & & & $+138 \%$ \\
\hline
\end{tabular}

Please note that the \%age increase figures do not take account of the shorter time period of the first year

Fig. 8 Percentage increase in growth of service take-up during the first two years 


\section{Methods of recording statistics}

Whilst some of the statistics are taken from the computer-based Unicorn library management system, the complexity of information required by the Unit resulted in many statistics being recorded manually. All team members record statistics as completed paperwork is filed for each service. When a completed request form for each service is filed in the appropriate box file for each department, it is recorded on a monthly sheet within that box as a series of fivebar gates. Monthly totals are then taken from each service for each academic department. The figures are entered into Microsoft Excel worksheets for each department, which feed into other worksheets to produce the two other different sets of monthly statistics, a library management worksheet, and a University management worksheet.

Although students can send requests for services through the web catalogue, many are received by post, fax, email or telephone. Team members do not enter details of all requests on to the library management system, as this would add an unnecessary stage to many procedures. Photocopy requests are a good example of this, in that we may receive a signed Copyright declaration form, the item is retrieved from the library shelves, the photocopying is done and despatched to the student as soon as possible. The form is then filed as described above. Requests such as these are not entered on to a computer and a manual counting method is, therefore, essential.

The statistics produced by the Unicorn library management software include logons by distance learning students to the web catalogue and the total number of loans issued to distance learning students. These reports are possible because a separate user profile was established in January 2000 for distance learning students. This has proved invaluable in producing statistics and targeting this group for email notices or specific services. The figures obtained from Unicorn are entered into the Excel worksheets so that they can be presented in a variety of graphical formats as required.

The combination of manual and computer based statistics complement each other in providing useful information to service managers. Whilst the number of postal loans sent to distance learning students in August 2000 was 123 (recorded manually), the total number of loans for distance learners for that month was 910. This illustrated that distance learners visit the Library and issue books in person, which had not been anticipated. The surge in August is the result of a week-long residential summer school.

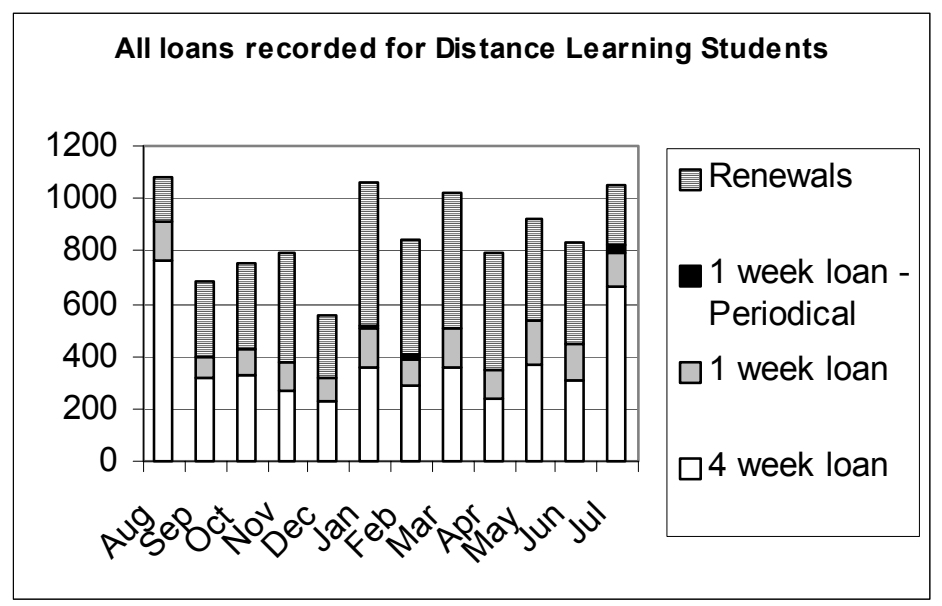

Fig. 9 Patterns of library stock use by all distance learning students 1999/2000 


\section{Summary of information collected for all services}

The following table briefly describes how and what information is collected in relation to each service.

\begin{tabular}{|c|c|c|}
\hline Service & Method & Type of data collected \\
\hline Postal book loans & Manual & $\begin{array}{l}\text { Monthly by department: number requested, } \\
\text { number supplied }\end{array}$ \\
\hline $\begin{array}{l}\text { Loans by distance } \\
\text { learners }\end{array}$ & Computer & Totals \\
\hline Document delivery & Manual & $\begin{array}{l}\text { Monthly by department; number of } \\
\text { interlibrary loans, number of photocopies } \\
\text { from library stock, number not supplied }\end{array}$ \\
\hline Enquiries & Manual & $\begin{array}{l}\text { Monthly by department; enquiry method, } \\
\text { enquiry subject, number of UK and non-UK }\end{array}$ \\
\hline Literature searches & Manual & $\begin{array}{l}\text { Monthly by department; number of searches } \\
\text { sent, number of advice and help sessions } \\
\text { provided }\end{array}$ \\
\hline $\begin{array}{l}\text { Information skills } \\
\text { sessions }\end{array}$ & Manual & $\begin{array}{l}\text { Monthly by department; number of students } \\
\text { attending, time taken }\end{array}$ \\
\hline $\begin{array}{l}\text { Webcat logins by } \\
\text { distance learners }\end{array}$ & Computer & Totals \\
\hline $\begin{array}{l}\text { Contact with academic } \\
\text { department staff }\end{array}$ & Manual & $\begin{array}{l}\text { Monthly by department; number of contacts } \\
\text { made by or with department staff }\end{array}$ \\
\hline $\begin{array}{l}\text { Arrangements with other } \\
\text { libraries }\end{array}$ & Manual & $\begin{array}{l}\text { Monthly by department; number of UK } \\
\text { Libraries Plus provisions, number of } \\
\text { payments for external borrower membership }\end{array}$ \\
\hline
\end{tabular}

Fig. 10 Statistics collection for each service.

Some of these methods have been adapted or changed during the first two years. One example of this is in the way information skills training sessions are recorded. Information skills training is offered to distance learning students in a number of formal and informal ways. The formal training sessions carried out by Unit staff at academic department study days and residential events were initially recorded as one event. This has recently been refined to record the number of students present and time spent at each session. Students are also offered one-to-one sessions when they visit the Unit, either by appointment or on a drop-in basis. These were originally counted as a visit on the enquiry statistics sheets, but have more recently been recorded as an information skills session to comply with changing SCONUL and local requirements.

The difficulty of deciding where to record information can present a few challenges. Many of our enquiries are multi-faceted and do not easily fit into one neat category. E-mails and telephone calls often require comprehensive guidance sessions, which are usually counted as an enquiry, but could easily qualify as an information skills support session. Similarly, requests for literature searches and the resulting communications with students often result in significant information skills support. The Unit now counts advice sessions and guidance that result from literature search requests. These are expected to increase, as more students are encouraged to carry out their own searches.

\section{Qualitative information}

In addition to counting the number of requests and completed activities within the Unit we are also concerned about the quality and effectiveness of the services. Whilst harder to measure, 
we have received considerable feedback about this from students and academics as individual comments or through the University Library 'Comments, Compliments and Complaints' form, available in print and on the web site. Evaluation forms completed after user education sessions often produce a range of positive comments about both the training offered, the web site and the services provided.

QAA subject review exercises often comment on the quality of services offered by the Unit and the QAA Continuation Audit for the University 'noted the professionalism of the creative approach which had been adopted in the development and evaluation of the virtual library development for distance-learners, and commends the effectiveness of its speedy dissemination to colleagues and to distance-learning students.' (QAA, 2001).

Both distance learning students and academic staff have responded positively to the Unit during the first two years. We have received many comments, which have been recorded on the web site. Many students who started studying before the service was established commented on the difference the service made to their experience at the University. Several students have identified the service as having a direct impact on their marks for assignments and dissertations. This feedback has provided great encouragement to the team offering this service. The following is an example from a student studying Archaeology by distance learning:

"...one of the most valuable additions to my program was access to the Library Distance Learning Unit...I realize the pressure you are under to perform at reasonable cost and to demonstrate added value to the people you serve. Let me assure you, that you and your staff do both. I have taken the liberty of using your example in discussing such special library units with Universities here in the U.S. I hope we can learn from your example."

We know that students who use the Unit feel they receive a quality service, and we are about to carry out a detailed user survey, which will also target those who have not yet used the services offered. The survey will be advertised by an e-mail notice and made available on the web site to return either electronically or by post. Students will be asked to identify which services they have used and how timely and appropriate these were. They will also be asked about their use of our interactive web-based tutorials, which are available on the Unit's information skills web page. We have found it difficult to obtain feedback on the effectiveness of these, despite offering the opportunity for students to send quiz answers to the Unit for comment. We plan to develop some web tutorials that can be used during formal information skills sessions and evaluated with an audience of distance learning students.

\section{Conclusion}

Motivating staff to keep up consistent data recording can be a challenge when statistics often appear to be collected for an indefinable reason. The effort and commitment from the staff of the Unit in collecting these statistics has been rewarded in several ways and all team members understand the importance of this time consuming activity. The temporary increase in staffing levels to cope with the demands of student registrations at an early stage reinforced this in a very positive way. The statistics provided tangible evidence of work overload and library managers were in a position to respond to this.

The chart and table, shown in figures 7 and 8, which were presented to University managers and heads of academic departments offered numerical confirmation that take-up of the service during the first two years was as good, if not better, than expected. At the same presentation, 
qualitative comments from students from all academic departments were displayed. In addition some students attended the session to give their support to a service that had provided a significant contribution to their course experience with the University. There is no question that these factors have influenced the continuation of the service beyond the three years for which it was initially funded.

The fact that manual recording of statistics currently outweighs the information we retrieve from the library management system will need to be addressed in the future. Breaking the data down by department and location of students provides invaluable information for academic departments. The Distance Learning Unit is working closely with the library's system team to consider how we can manipulate the Unicorn system to provide more of this information. In the meantime, the team will continue to groan about the level of recording that needs to be carried out, and the library managers will continue to use this information to improve and modify the service.

\section{References}

The Quality Assurance Agency for Higher Education (2001) Quality audit report: University of Leicester: 2001 Gloucester: QAA 20-21

Robinson, D. (2000) Performance measurement and performance indicators: a selective bibliography URL: http://www.nlc-bnc.ca/6/7/s7-1000-e.html [2002, February 26]

Winkworth, I. (1999) Performance measurement of U.K. University Libraries, ARL bimonthly report 207 URL: http://www.arl.org/newsltr/207/ukperfmeas.html [2002, February 26] 